\title{
Pengembangan Kapasitas Kelompok Usaha Bersama (KUBE) Tabadiku Tongole melalui Kerajinan Bambu Tutul
}

\author{
Mohbir Umasugi, Anfas, Lisda Ariani Simabur \\ UPBJJ Universitas Terbuka Ternate \\ mohbir@ecampus.ut.ac.id, anfas_st_mm@ecampus.ut.ac.id, lisda.simabur@ecampus.ut.ac.id
}

\begin{abstract}
Abstrak
Pemberdayaan masyarakat telah menampakkan dirinya sebagai pendekatan yang banyak dianut dan banyak mewarnai banyak kebijakan pembangunan masyarakat dan juga merupakan sarana untuk mengubah kehidupan sosial dan ekonomi masyarakat melalui potensi yang ada di masyarakat namun kurang mendapat perhatian atau dukungan dari pemerintah. Hal ini dirasakan oleh masyarakat di Kelurahan Marikurubu, Kecamatan Ternate Tengah. Wilayah ini memiliki potensi tradisional yang khas dari bambu, namun hingga kini belum dikembangkan secara maksimal. Padahal potensi ini bisa menjadi pemasukan untuk menambah pendapatan masyarakat setempat yang dapat digunakan untuk meningkatkan kesejahteraan mereka. Maka dari itu, dengan adanya pengabdian kepada masyarakat (PkM) Universitas Terbuka hadir untuk memberdayakan potensi Kelompok Usaha Bersama (KUBE) yang telah ada menjadi lebih optimal. Masalah yang dihadapi perajin kursi dan aksesori tradisional berbahan bambu di Kelurahan Marikurubu begitu kompleks. Masalah-masalah tersebut di antaranya dibatasi modal usaha, kurangnya tenaga terampil yang bisa membuat berbagai jenis kerajinan, juga terbatasnya peralatan pembuatan kerajinan. Selain itu, keterbatasan juga terdapat pada pemasaran hasil kerajinan serta minimnya sentuhan yang datang dari luar, baik dari pemerintah maupun pihak lainnya. Adapun maksud dari rencana pelaksanaan pengabdian kepada masyarakat ini ialah untuk membuka peluang usaha bagi masyarakat. Hal ini terutama pada masyarakat kurang mampu yang memiliki keterampilan dan keinginan untuk mendapatkan penghasilan. Cakupan dalam kegiatan ini adalah untuk memperbaiki ekonomi keluarga secara mandiri terutama kepada mereka yang tergabung dalam Kelompok Usaha Bersama Tabadiku Tongole.
\end{abstract}

Kata Kunci: kelompok usaha bersama, kerajinan bambu tutul.

\section{Capacity Building for Joint Business Groups Tabadiku Tongole through Bambu Tutul Crafts}

\begin{abstract}
Community empowerment has shown itself as an approach that is widely adopted and has colored many community development policies and is also a means to change the social and economic life of the community through the potential that exists in society but does not receive enough attention or support from the government. This is felt by the people in Marikurubu Village, Central Ternate District. This region has the unique traditional potential of bamboo, but until now it has not been fully developed. In fact, this potential can be used as income to increase local community income which can be used to improve their welfare. Therefore, with the presence of community service, Universitas Terbuka is here to empower the potential of the existing Joint Business Group to be more optimal. The problems faced by craftsmen of traditional bamboo chairs and accessories in Marikurubu Village are complex. These problems include limited business capital, a lack of skilled workers who can make various types of handicrafts, as well as limited handicraft-making equipment. In addition, limitations also exist in the marketing of handicraft products and the lack of touches that come from outside, both from the government and other
\end{abstract}


parties. The purpose of this community service implementation plan is to open up business opportunities for the community. This is especially so for the less fortunate who have the skills and desire to earn income. The scope of this activity is to improve the family economy independently, especially for those who are members of the Tabadiku Tongole Joint Business Group.

Keywords: joint business group, Bambu Tutul handicrafts

\section{PENDAHULUAN}

Kota Ternate terdiri dari delapan pulau yaitu Ternate, Moti, Hiri, Mayau, Tifure, Maka Mono, dan Garida (tiga pulau terakhir tidak berpenghuni), selanjutnya Kota Ternate sendiri terdapat lima kecamatan yakni Pulau Ternate, Ternate Barat, Ternate Selatan, Ternate Tengah, dan Ternate Utara. Kota Ternate sebagian besar daerahnya berbukit, yang menjadi lokasi pelaksanaan Pengabdian kepada Masyarakat (PkM) yaitu di lingkungan Tongole, Kelurahan Marikurubu, Kecamatan Ternate Tengah. Kelurahan Marikurubu sendiri berada di daerah ketinggian.

Kelompok Usaha Bersama Tabadiku Tongole didirikan pada 2017, berdirinya kelompok usaha bersama ini memiliki visi dan misi meningkatkan taraf hidup masyarakat khususnya orang-orang yang tergabung dalam struktur kelompok usaha bersama ini, disisi lain kelompok usaha ini didirikan karena potensi dan sumber daya alam (bambu cina) atau yang lebih di kenal bambu bermotif yang sanggat banyak dan hanya terdapat di lingkungan Tonggole, Kelurahan Marikurubu. Usaha kerajinan bambu adalah di dirikan untung memenuhi permintaan pasar lokal seperti di Kota Ternate Khususnya dan di Provinsi Maluku Utara serta Seluruh Indonesia Umumnya.
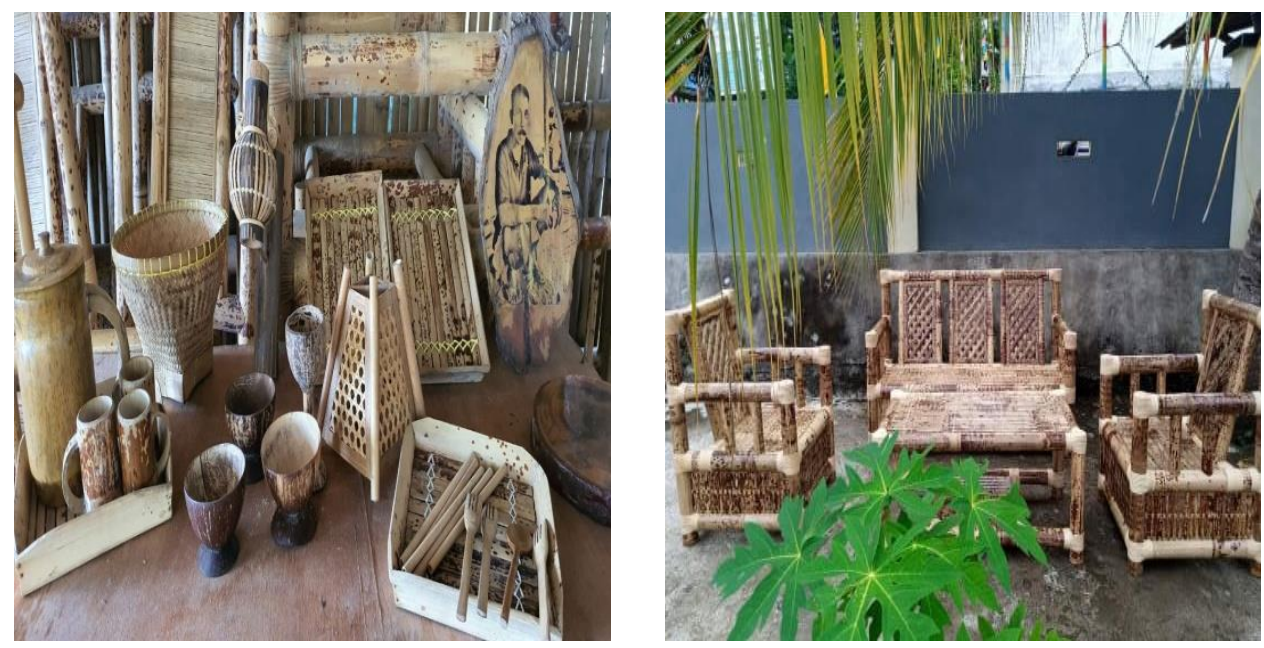

Gambar 1. Berbagai kerajinan yang dihasilkan oleh Kelompok Usaha Bersama (KUBE) Tabadiku Tongole

Kebutuhan akan produk kerajinan bambu Kelompok Usaha Bersama Tabadiku Tongole sanggat di minati karena memiliki ciri has serta berbagai pilihan atau jenis desain, atas dasar itulah peluang usaha akan kerajinan ini sanggat besar akan tetapi dalam pengembangannya dibatasi dengan masalah permodalan dan lainnya. Berdasarkan permasalahan di atas maka tim Pengabdian Kepada Masyarakat Dosen 
Vol. 1, No. 3,

November

2020

pp. $180-187$

e-ISSN:

2722-2004

Title

Capacity

Building for

Joint Business

Groups

Tabadiku

Tongole

through

Bambu Tutul

Crafts

Author

M. Umasugi, Anfas,

L. A. Simabur

Universitas Terbuka melihat hal ini sebagai potensi sumber daya yang perlu dikembangkan agar memajukan potensi ekonomi lokal terutama Kelompok Usaha Bersama Tabadiku Tongole dan masyarakat sekitar.

\section{Pemberdayaan Masyarakat}

Poin dari tahap ini memberikan hal-hal yang dibutuhkan untuk dapat mandiri dan menuju keberlanjutan. Dalam pelaksanaannya, pemberdayaan masyarakat dapat dilakukan secara bertahap dari tingkat individu, keluarga, kelompok, komunitas sampai pada tingkat institusi atau kelembagaan. Semuanya itu mencerminkan adanya bentuk partisipasi masyarakat. Partisipasi aktif dari seluruh lapisan masyarakat diharapkan akan menghasilkan pembangunan yang berkelanjutan. Pembangunan itu sendiri pada dasarnya merupakan suatu gerakan untuk menciptakan kehidupan yang lebih baik bagi seluruh lapisan masyarakat dengan peran aktif masyarakat dan berlandaskan atas inisiatif masyarakat lokal. Apabila inisiatif itu tidak muncul maka diperlukan upaya untuk mendorong tumbuhnya inisiatif tersebut (Riasih, 2010:168). Dalam proses ini harus tetap memperhatikan kekuatan dan kecakapan dari kelompok yang diperdayakan. Ini penting karena asas kebermanfaatan harus terus dijaga dengan menyesuaikan pelimpahan kekuasaan yang diberikan dengan kapasitas kelompok sasaran di lapangan.

Wujud konkret dari tahap ini seperti memberikan peluang promosi melalui pameran, memberikan alat untuk keberlanjutan program, serta hal-hal lain yang sifatnya adalah investasi jangka panjang untuk keberlanjutan kelompok sasaran untuk dapat mandiri tanpa intervensi yang terlalu masif lagi dari kelompok luar atau pihak yang memberi daya tersebut. Pada tahap pendayaan, Tim Pengabdian kepada Masyarakat akan membuat praktik pembuatan kerajinan dari bambu tutul yang merupakan hasil dari praktik bersama. Diharapkan melalui fasilitas ini, ke depan masyarakat yang terlibat dalam kegiatan PkM di Lingkungan Tongole, Kelurahan Marikurubu dapat lebih partisipatif dengan memanfaatkan potensi bambu tutul yang ada di sekitar mereka.

\section{Pengembangan Kapasitas (Capacity Building)}

Dengan adanya pengembangan kapasitas diharapkan mampu mengubah tatanan masyarakat yang ditegaskan oleh Sugeng (2010:154). Adapun strategi pengembangan kapasitas kelembagaan tersebut dapat dikaji melalui dimensidimensi kultural, struktural, maupun interaksional. Dimensi kultural meliputi sistem nilai, etika, dan norma yang ada; dimensi struktural berkaitan dengan keberadaan lembaga sebagai medium untuk mengangkat derajat kehidupan sosial ekonomi para anggotanya; dimensi interaksional berkaitan dengan kelembagaan yang mampu mengembangkan jejaring sosial demi kemajuan anggota maupun komunitas di dalamnya; sedangkan dimensi sumber daya manusia meliputi pengetahuan, keterampilan, dan sikap.

Pengembangan kapasitas selanjutnya dipahami sebagai suatu proses peningkatan atau perubahan perilaku individu, organisasi, dan sistem masyarakat dalam mencapai tujuan yang telah ditetapkan secara efektif dan efisien; yaitu sebagai strategi untuk meningkatkan daya dukung kelembagaan dalam mengantisipasi masalah dan kebutuhan yang dihadapi (Sugeng, 2010:154).

Jika dilihat dari proses perubahan yang terencana maka yang direncanakan adalah tindakan untuk membangun aspek manusianya termasuk proses 
interaksinya dalam masyarakat, bukan membangun benda. Oleh sebab itu, tidak salah apabila dalam pengembangan kapasitas masyarakat terkandung makna pengembangan kapasitas manusianya sebagai aktor yang membentuk masyarakat. Dalam penyebarannya, pengembangan kapasitas manusia ini dapat berupa pengembangan wawasan dan tingkat pengetahuan, peningkatan kemampuan untuk merespons dinamika lingkungannya, peningkatan kemampuan, peningkatan akses dalam proses pengambilan keputusan. Sebagai perubahan yang terencana, yang direncanakan adalah sebagaimana memberikan rangsangan dan dorongan agar masyarakat terbangun dan berkembang kapasitasnya (Soetomo, 2009:251).

Pada tahap pengapasitasan ini, Tim PkM akan melaksanakan sosialisasi, simulasi dan kampanye terkait program Pengembangan Kapasitas Kelompok Usaha Bersama (KUBE) Tabadiku Tongole. Dalam tahap sosialisasi akan ditekankan pemanfaatan dan penggunaan bambu tutul sebagai kerajinan yang memiliki nilai jual, di samping itu akan dilakukan simulasi pembuatan kerajinan yang diproyeksi menjadi oleh-oleh khas Kota Ternate, Selain sosialisasi dan simulasi juga dilakukan kampanye penggunaan bambu tutul sebagai alat makan dan minum demi mengurangi dampak limbah plastik. Semua tahapan ini akan di publikasi melalui media cetak dan media sosial berbagai pihak.

\section{Kelompok}

Salah satu upaya membangkitkan inisiatif dan partisipasi masyarakat lokal dapat dilakukan dengan menggunakan medium kelompok. Pendekatan kelompok menurut Riasih (2010:168), mempunyai kelebihan antara lain proses adopsi dapat dipercepat, karena adanya interaksi sesama anggota kelompok dalam bentuk saling mempengaruhi satu sama lain. Hal senada dikemukakan oleh Huraerah (2011:51), bahwa beberapa kebutuhan manusia ada yang hanya dapat dipenuhi melalui kelompok dan terdapat kemampuan-kemampuan manusia yang hanya dapat dikembangkan melalui kelompok. Pemberdayaan kelompok juga dapat diartikan sebagai salah satu upaya untuk membangun daya dengan mendorong, memotivasi dan membangkitkan kesadaran akan potensi yang dimilikinya serta berupaya untuk mengembangkan pengetahuan, dan meningkatkan segala usaha masyarakat dalam memenuhi kebutuhannya guna mencapai kemakmuran hidup dalam berkelompok.

Bertitik tolak dari hal tersebut, maka melalui kelompok dinilai sebagai bentuk pemberdayaan yang paling efektif, seperti yang dikemukakan Riasih (2010:169), bahwa lebih mudah untuk mengubah pola tingkah laku individu-individu yang terikat dalam suatu kelompok daripada secara individual. Dengan demikian, penggunaan kelompok merupakan mekanisme yang lebih baik daripada mekanismemekanisme lainnya dan bahwa kelompok memiliki kekuatan-kekuatan tertentu yang apabila digali dan dikembangkan atas nama dan kerja sama kelompok dapat merupakan sumber-sumber untuk penyembuhan dan pengembangan anggotaanggotanya. Lebih lanjut Riasih (2010:169), menambahkan kelompok adalah sejumlah orang yang memiliki kesamaan norma, nilai dan harapan-harapan, serta melakukan interaksi secara sadar dan teratur. Dari pengertian tersebut bahwa unsurunsur kelompok terdiri atas: (1) Sejumlah orang, (2) Memiliki kesamaan norma, (3) Melakukan interaksi secara sadar dan teratur. 


\section{METODE PELAKSANAAN}

Vol. 1, No. 3,

November

2020

pp. $180-187$

e-ISSN:

2722-2004

Title

Capacity

Building for

Joint Business

Groups

Tabadiku

Tongole

through

Bambu Tutul

Crafts

Author

M. Umasugi, Anfas,

L. A. Simabur

Berdasarkan permasalahan mitra yang telah dipaparkan di atas maka, terdapat beberapa metode intervensi yang akan dilakukan oleh Tim PkM untuk menjawab permasalahan kegiatan dalam program Pengembangan Kapasitas Kelompok Usaha Bersama (KUBE) Tabadiku Tongole melalui Kerajinan Bambu Tutulini adalah:

1. Sosialisasi, Simulasi dan Kampanye.

Sosialisasi Pengembangan Kapasitas Kelompok Usaha Bersama Melalui Kerajinan Bambu Tutul ini dilakukan pada kalangan masyarakat di tingkat Rukun Tetangga/ Rukun Warga (RT/RW) Lingkungan Tongole, Kalurahan Marikurubu dan terkhusus untuk masyarakat yang tergabung dalam KUBE Tabadiku Tongole yang terkait dengan penelitian PkM. Sosialisasi juga akan dibantu dari pengrajin bambu tutul yang sudah lama menekuni kerajinan tersebut. Untuk lebih memaksimalkan hasilnya dalam sosialisasi pemanfaatan bambu tutul maka akan dilakukan simulasi atau pembuatan melalui maket miniatur kerajinan dari bambu tutul sebagai wadah pembelajaran bagi kelompok sasaran. Selain sosialisasi dan simulasi juga dilakukan kampanye menggunakan bahan alam untuk mengurangi dampak sampah plastik.

2. Pembuatan Kerajinan Bambu Tutul

Pembuatan kerajinan bambu tutul akan dibantu oleh pengrajin bambu tutul yang sudah lama menekuni kerajinan tersebut. Mencermati potensi bambu tutul yang ada di Lingkungan Tongole, Kelurahan Marikurubu, Kecamatan Ternate Tengah, maka perlu dilakukan upaya-upaya dalam rangka untuk memanfaatkan potensi bambu tutul yang ada. Upaya-upaya dimaksud dalam bentuk pembuatan kerajinan bambu tutul yang telah akan dilakukan oleh Tim PkM dengan Kelompok Usaha Bersama (KUBE) Tabadiku Tongole.

\section{HASIL DAN PEMBAHASAN}

\section{Metode Intervensi}

Berdasarkan permasalahan mitra yang telah dipaparkan di atas maka, terdapat beberapa metode intervensi yang akan dilakukan oleh Tim PkM untuk menjawab permasalahan kegiatan dalam program Pengembangan Kapasitas Kelompok Usaha Bersama (Kube) Tabadiku Tongole Melalui Kerajinan Bambu Tutulini adalah:

1. Sosialisasi, Simulasi dan Kampanye.

Sosialisasi Pengembangan Kapasitas Kelompok Usaha Bersama Melalui Kerajinan Bambu Tutul ini dilakukan pada masyarakat yang tergabung dalam KUBE Tabadiku Tongole. Untuk lebih memaksimalkan hasilnya dalam sosialisasi pemanfaatan bambu tutul maka akan dilakukan simulasi atau pembuatan melalui maket miniatur kerajinan dari bambu tutul sebagai wadah pembelajaran bagi kelompok sasaran.

2. Pembuatan Kerajinan Bambu Tutul

Pembuatan kerajinan bambu tutul akan dibantu oleh pengrajin bambu tutul yang sudah lama menekuni kerajinan tersebut. Mencermati potensi bambu tutul yang ada di Lingkungan Tongole, Kelurahan Marikurubu, Kecamatan Ternate Tengah, maka perlu dilakukan upaya-upaya dalam rangka untuk memanfaatkan 
potensi bambu tutul yang ada. Upaya-upaya dimaksud dalam bentuk pembuatan kerajinan bambu tutul yang telah akan dilakukan oleh Tim PkM dengan Kelompok Usaha Bersama (KUBE) Tabadiku Tongole.

\section{Luaran}

Hasil dari kegiatan Pengabdian kepada Masyarakat ini yaitu:

1. Society awareness atau kesadaran masyarakat tentang pemanfaatan bambu tutul sesuai dengan kebutuhan masyarakat Lingkungan Tongole, Kelurahan Marikurubu, Kecamatan Ternate Tengah. Society awareness diharapkan dapat dijadikan sebagai informasi yang diterima masyarakat sehingga dapat memanfaatkan potensi alam yang dimiliki dari lingkungan sekitar mereka sendiri.
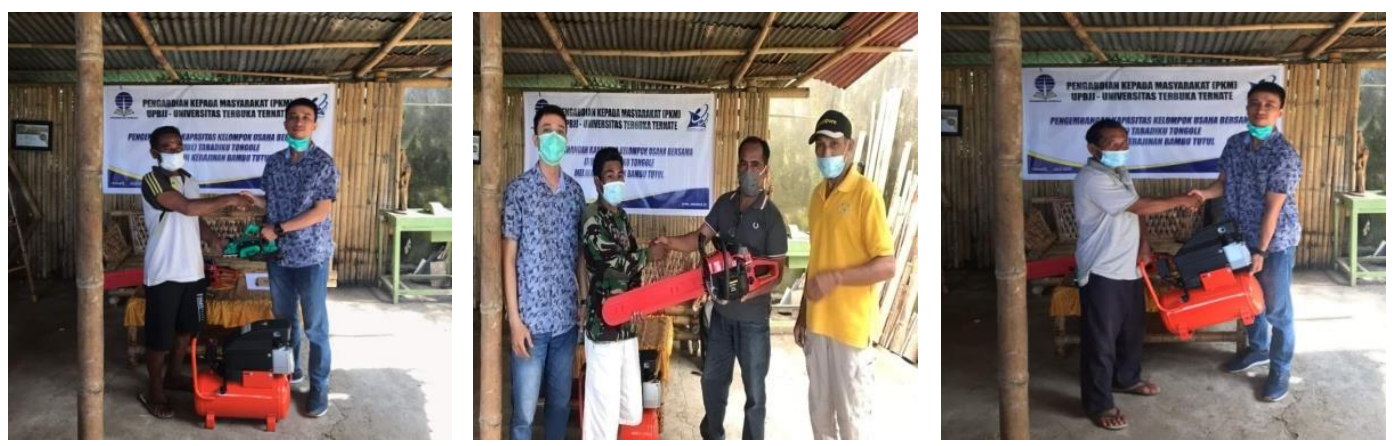

Gambar 2. Penyerahan alat-alat berupa mesin sensor, skaf strom, dan kompresor sebagai alat pendukung pembuatan kerajinan Bambu Tutul

2. Sosialisasi, simulasi dan kampanye untuk masyarakat Lingkungan Tongole, Kelurahan Marikurubu, Kecamatan Ternate Tengah. Sosialisasi akan dilakukan kepada Kelompok Usaha Bersama (KUBE) Tabadiku Tongole untuk pemanfaatan bambu tutul secara baik, selain itu akan dilakukan simulasi melalui maket miniatur kerajinan dari bambu tutul yang bisa dijadikan oleh-oleh khas Kota Ternate. Selain sosialisasi dan simulasi juga dilakukan kampanye menggunakan bahan alam untuk mengurangi dampak sampah plastik.

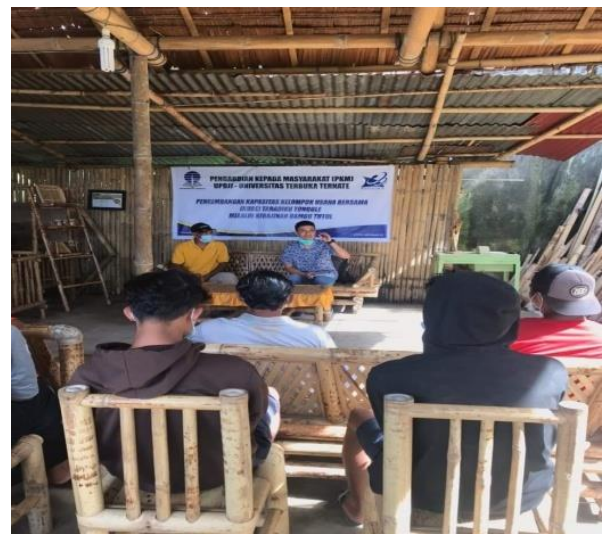

Gambar 3. Sosialisasi, simulasi, dan kampanye dilakukan oleh Tim PkM UPBJJ-UT Ternate

3. Pembuatan kerajinan dari bambu tutul akan dilakukan Tim PkM bersama-sama dengan Kelompok Usaha Bersama (KUBE) Tabadiku Tongole, kerajinan bambu ini akan diprioritaskan menjadi hasil kerajinan tangan berbahan dasar alam yang 
nantinya menjadi oleh-oleh khas Kota Ternate, selain itu hasil kerajinan ini ditargetkan akan menjadi salah satu objek pendapatan bagi masyarakat

Vol. 1, No. 3, November 2020

pp. 180-187 e-ISSN:

2722-2004

Title

Capacity

Building for

Joint Business

Groups

Tabadiku

Tongole

through

Bambu Tutul

Crafts

Author

M. Umasugi, Anfas, L. A. Simabur
Lingkungan Tongole, Kelurahan Marikurubu, Kecamatan Ternate Tengah.

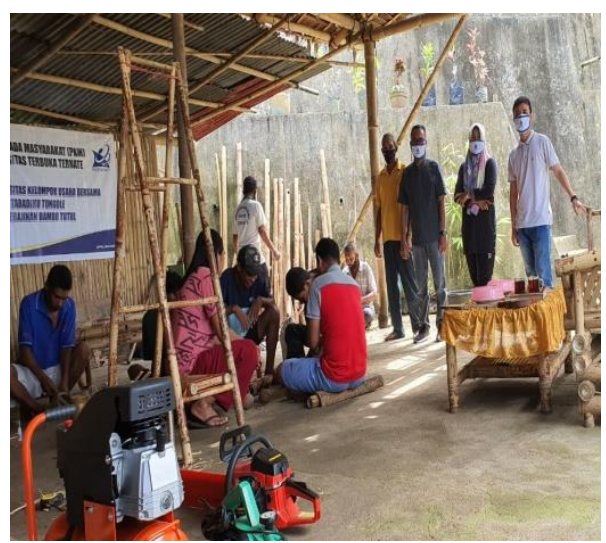

Gambar 4. Pembuatan Kerajinan Bambu Tutul Oleh Kelompok Usaha Bersama (KUBE) Tabadiku Tongole

4. Publikasi jurnal. hasil abdimas atau Pengabdian kepada Masyarakat (PkM) dengan judul Pengembangan Kapasitas Kelompok Usaha Bersama (Kube) Tabadiku Tongole melalui Kerajinan Bambu Tutul ini akan dikemas dalam sebuah artikel kemudian diterbitkan dalam jurnal Univeristas Terbuka atau jurnal lokal di Universitas yang ada di Indonesia.

5. Publikasi Kegiatan PkM di Media Cetak Lokal. Kegiatan Pengabdian Kepada Masyarakat tentang Pengembangan Kapasitas Kelompok Usaha Bersama (Kube) Tabadiku Tongole Melalui Kerajinan Bambu Tutul akan dipublikasikan di salah satu media cetak lokal yaitu Malut Post.

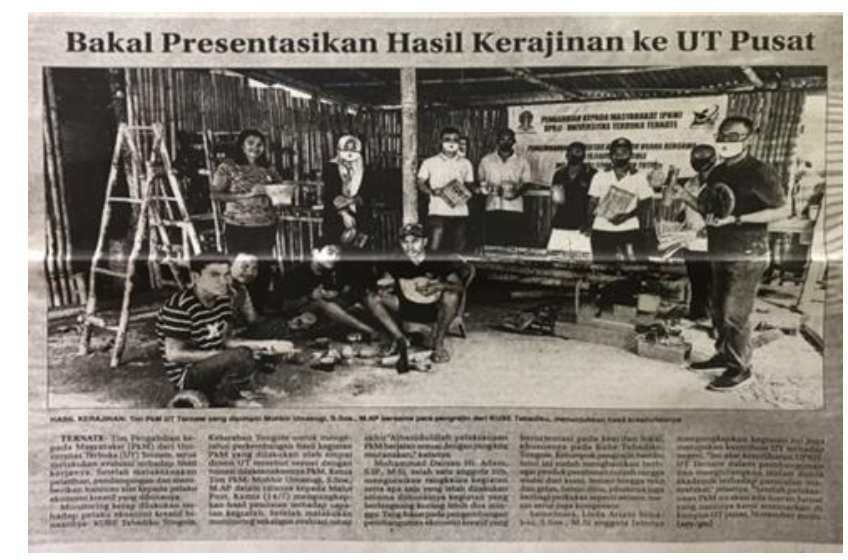

Gambar 5. Publikasi Media Cetak Malut Post

\section{SIMPULAN}

Industri kecil sebagai salah satu sektor informal, penting dalam menopang perekonomian masyarakat, karena merupakan bentuk usaha yang bisa dilakukan secara perorangan dan atau kelompok. Pengembangan Kapasitas Kelompok Usaha Bersama (Kube) Tabadiku Tongole melalui kerajinan bambu tutul adalah bentuk industri, di mana di dalamnya terdapat ciri-ciri industri kecil yang harus di sentuh 
dengan pemberdayaan dan pengembangan kapasitas kelompok demi memiliki sumber daya manusia yang unggul di bidangnya untuk menuju pada kemandirian di antaranya terbentuk peningkatan penghasilan serta keberlangsungan usaha dalam skala kecil dan biasanya dilakukan oleh keluarga sendiri maupun kelompok.

Industri ini layak untuk direkomendasikan kepada Pemerintah Daerah Kota Ternate agar mau memperhatikan dan mempertimbangkan alternatif penyusunan rencana strategis untuk dijadikan bahan kajian yang mendalam oleh Pemerintah Daerah Kota Ternate dalam membuat kebijakan yang ditujukan kepada para kelompok perajin bambu tutul di Kelurahan Tongole. Cara untuk melaksanakan alternatif konsep kebijakan yang direkomendasikan dalam pengabdian kepada masyarakat ini adalah dengan melakukan kerja sama antara pihak Pemerintah Kota, Lembaga Keuangan, dan masyarakat kelompok pengrajin bambu tutul.

\section{DAFTAR PUSTAKA}

Huraera, A. (2011). Pengorganisasian dan Pengembangan Masyarakat, Model dan Strategi Pembangunan Berbasis Kerakyatan. Cetakan Kedua. Bandung: Humaniora

Riasih, T. (2010). Modal Sosial Kelompok Pekerja Informal. Dalam Fahrudin, A. (ed),Pemberdayaan Partisipasi dan Penguatan Kapasitas Masyarakat. Bandung: Humaniora

Soetomo. (2009). Pemberdayaan Masyarakat: Mungkinkah Muncul Antitesisnya. Yogyakarta: Pustaka Pelajar

Sugeng, B. (2010). Pengembangan Kapasitas dan Keberfungsian Sosial. Dalam Fahrudin, A. (ed), Pemberdayaan Partisipasi dan Penguatan Kapasitas Masyarakat. Bandung: Humaniora 